\title{
Change comes slowly to South Africa
}

Reviving the fortunes of South African science after years of political isolation is proving an uphill task. The needs are enormous, while funding remains as tight as ever. Nevertheless many researchers remain optimistic.

HALF-wAY through its five-year term of office, South Africa's Government of National Unity is still far from meeting the high hopes of its scientific community that the ending of apartheid would lead to a blossoming of research activities.

Part of the reason has been financial. Not only has the economy remained weak, but - perhaps understandably - basic research has not been at the top of the new government's economic priorities. But there have also been political factors at work.

One reason for the initial high hopes, for example, was the creation by President Nelson Mandela of a Department for Arts, Culture, Science and Technology (DACST). But the ministerial portfolio was allocated to the Inkatha Freedom Party (IFP), the not-toocosy bedfellow of the African National Congress. Indeed, it now appears that the creation of a specific portfolio for science and technology may have paradoxically undermined their development.

The first minister, Ben Ngubane, a physician, proved very effective at charming foreign governments.

But he was less successful in persuading his own government to reverse trends in research spending. His successor, Lionel Mtshali, has been in office for only two months, and, unsurprisingly, has so far made little impact.

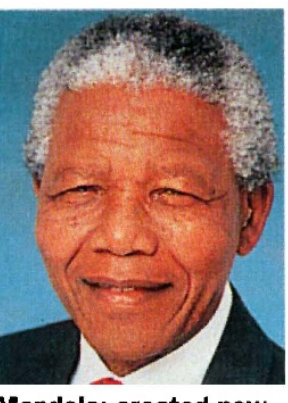

Mandela: created new science ministry.

The political reality is that Inkatha remains marginalized - and thus relatively powerless - in the cabinet, and that despite the best efforts of both incumbents, research has not escaped unscathed.

Yet despite the difficulties it faces, South African science is far from withering, and is certainly benefiting from wider international recognition and acceptance. "Although science wasn't nearly as badlyhit by the academic boycott as the humanities, the real worth of many South African scientists is now being recognized in many international fora," says Cliff Moran, dean of the science faculty at the University of Cape Town.

Briefing was written by Michael Cherry, Nature's South Africa correspondent. Current exchange rate: US $\$ 1=\mathrm{R} 4.68$
But Moran cautions that "the declining rand has had a more important effect than the advent of democracy on the state of science in the country". In fact, the rand has dropped steadily against most international currencies, including both the dollar and the pound sterling. This collapse in value has, in particular, had a crippling effect on the cost of scientific equipment, most of which is imported, and on the purchase of international journals.

There are plenty of optimists. "You shouldn't underestimate the power of fairy tales," says Alec Erwin, minister of trade and Industry. But, despite South Africa's remarkable achievement of political reconciliation, the country's economic recovery has been agonisingly slow, and its prolonged recession, from which it is yet to emerge, has hit research hard.

Between 1985 and 1991, spending on research and development stood at about one per cent of the gross domestic product. But figures released earlier this year show that in 1993/94, the last year of the National Party government, this figure had dropped to 0.75 per cent.

The drop in funding has been matched by a decline in South Africa's share of the international production of research papers, as reflected in publications listed by the Institute for Scientific Information (ISI) in Philadelphia. This rose constantly during the 1980 s, peaking in 1987 , with particular strengths in fields such as botany, zoology and clinical medicine (see page 13).

But according to Anastassios Pouris, an independent science policy consultant, this share of the world's scientific output has been in decline ever since, and countries like China, Taiwan, Brazil and Norway, which were either below or on a par with South Africa 15 years ago, have now passed it.

Furthermore, while the number of papers listed by ISI has been constant since 1987 at approximately 3,300 a year - more than 60 per cent of these publications are now produced by researchers at only five universities: Cape Town, Witwatersrand (in Johannesburg), Pretoria, Natal and Stellenbosch (near Cape Town). By comparison, says Pouris, the seven research councils, which employ the majority of the country's researchers, produce fewer than 200 ISI publications a year between them.

Many South African scientists acknowledge that there are some areas of science in which the country cannot pretend to compete with western countries. "We have to identify market niches in science and go for them," says Moran at Cape Town. "I am confident that we can do this successfully with the resources at our disposal," he adds.

The need to identify scientific priorities for South Africa has been accepted by the

\section{IMAGE UNAVAILABLE FOR COPYRIGHT REASONS}

Aiming high: the South African Astronomical Observatory's 1.9-m telescope in Sutherland.

new department, which has embarked - at great expense - on two ambitious projects: an audit of all the country's research activities, and a foresight exercise, which is intended to "identify those areas of science and technology that are likely to yield the greatest economic and social benefits for South Africa in the longer term".

Many hopes have been attached to a new white paper on science and technology, published in September (see page 12). But the changes implied by this document have yet to be effected. Similarly, a National Commission on Higher Education has made proposals for significant reforms in this sector. But their implementation is likely to be thwarted by political and other difficulties.

But despite the challenges still faced and the slow progress experienced so far, many South African scientists remain optimistic that a renaissance is still just around the corner.

\section{On other pages}

Restructuring research bodies

- Scientific strengths

- Plans for university funding

- School reforms struggle on

- Managing museums

- International contacts revive 